\title{
PENERAPAN KUALITAS LAYANAN BERDAMPAK PADA KEPUTUSAN PEMBELIAN PRODUK PAO PAO
}

\author{
Liliana Dewi \\ Program Studi International Business Management \\ Fakultas Manajemen dan Bisnis Universitas Ciputra Surabaya \\ UC Town, Citraland, Surabaya \\ Ldewi@ciputra.ac.id \\ Joy Victoria Dharmawan Lira \\ Program Studi International Business Management \\ Fakultas Manajemen dan Bisnis Universitas Ciputra Surabaya \\ UC Town, Citraland, Surabaya \\ joyvictoria36@gmail.com
}

\begin{abstract}
Zolid Agung Perkasa company is a company that runs in food \& beverage industry and has been established since February 2, 2015. This company sells product that named $\mathrm{Pao} \mathrm{Pao}$, that is, the product with a various food menu that are focus more on chinese food. This product is done because there in an opportunity in which nowadays many people want things all fast and affordable. The matter that is consumers who purchase Pao Pao products do not purchase that cause unstable sale. The purpose of this research in this study aims to know where the effect of service quality on consumer purchasing decision of Pao Pao. The total population that used in this research is 63 people. The sampling technique that in used in this research is non-probability sampling by using saturated sampling technique. The number of samples used 63 people. The analysis technique used in this research is multiple regression analysis technique using SPSS version 20. The result of this research shows that tangible (X1), reliability (X2), assurance (X3), responsiveness (X4), empathy (X5) significanty affect the purchasing decision (Y).
\end{abstract}

Keywords: quality service, tangible, reliability, assurance, responsiveness, empathy, purchase decision.

\footnotetext{
ABSTRAK

Perusahaan Zolid Agung Perkasa merupakan perusahaan yang bergerak di bidang industri food \& beverage dan telah berdiri sejak 2 Februari 2015. Perusahaan ini menjual produk yang bernama Pao Pao, yaitu produk dengan berbagai pilihan menu masakan yang lebih berfokus pada chinese food. Produk ini dibuat karena melihat adanya peluang di mana sekarang ini banyak orang ingin semua hal yang
} 
serba cepat dan terjangkau. Masalah yang terjadi adalah konsumen yang membeli produk Pao Pao tidak melakukan pembelian lagi yang menyebabkan penjualan tidak stabil. Penelitian ini bertujuan untuk mengetahui bahwa adanya pengaruh kualitas layanan terhadap keputusan pembelian konsumen Pao Pao. Jumlah populasi yang digunakan dalam penelitian ini adalah 63 orang. Teknik sampling yang digunakan dalam penelitian ini adalah non-probability sampling dengan menggunakan teknik sampling jenuh. Jumlah sampel yang digunakan 63 orang. Teknik analisis yang digunakan dalam penelitian ini adalah teknik analisis regresi berganda dengan menggunakan SPSS versi 20. Hasil penelitian ini menunjukkan bahwa bukti fisik (X1), keandalan (X2), jaminan (X3), ketanggapan (X4), empati (X5) secara signifikan berpengaruh terhadap keputusan pembelian (Y).

Kata kunci: kualitas layanan, bukti fisik, keandalan, jaminan, ketanggapan, empati, keputusan pembelian.

\section{PENDAHULUAN}

Perusahaan Zolid Agung Perkasa merupakan perusahaan yang bergerak di bidang industri food beverage dan berdiri sejak 2 Februari 2015. Ada lima orang anggota sebagai pendiri perusahaan. Perusahaan ini menjual produk yang bernama Pao Pao, yaitu produk dengan berbagai pilihan menu masakan yang lebih berfokus pada makanan chinese food. Perusahaan membuat produk ini karena melihat adanya peluang di mana sekarang ini banyak orang ingin semua hal yang serba cepat dan terjangkau. Selama masa penjualan, kendala yang dialami perusahaan dalam menjual produk $\mathrm{Pao} \mathrm{Pao}$ yaitu konsumen yang pernah membeli produk Pao Pao tidak melakukan pembelian lagi sehingga menyebabkan penjualan tidak stabil seperti terlihat pada Gambar 1.

Berdasarkan banyak faktor yang mungkin menjadi penyebab terjadinya ketidakstabilan tersebut, peneliti mencari tahu masalah apa yang paling banyak dikeluhkan yang dapat mempengaruhi keputusan pembelian konsumen Pao Pao, yaitu dengan melakukan wawancara singkat via chat line kepada 30 konsumen yang pernah membeli produk Pao Pao.

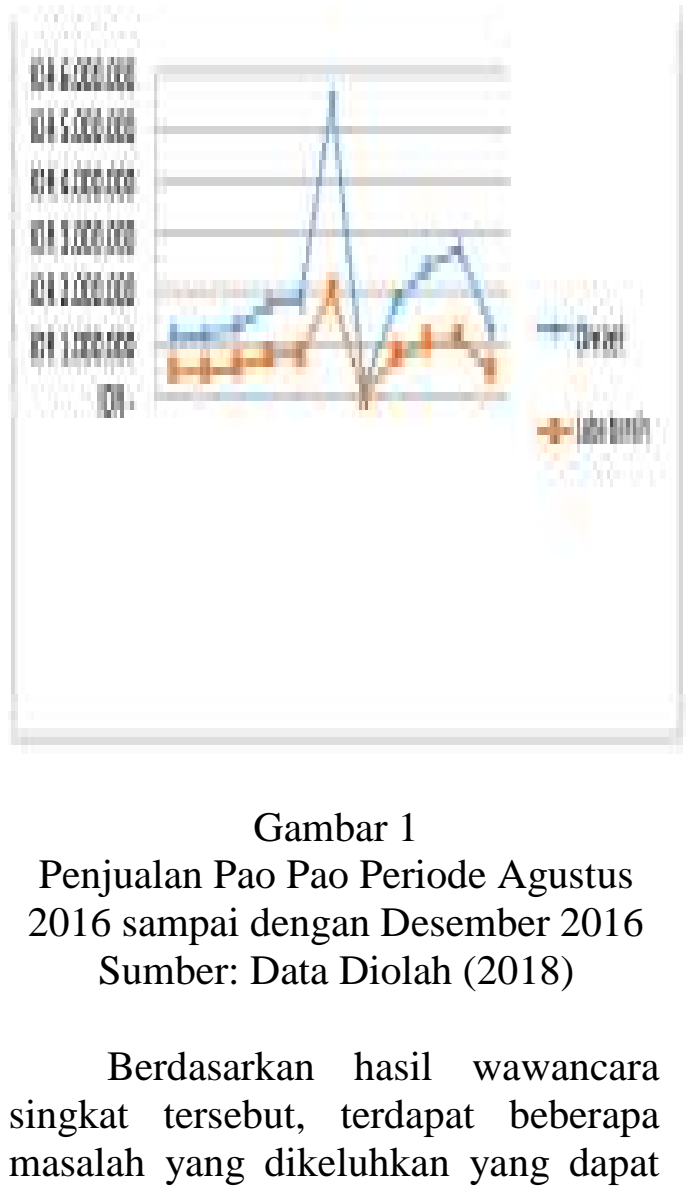


mempengaruhi keputusan pembelian konsumen. Dari hasil 30 konsumen yang diwawancara, 19 konsumen yang memiliki keluhan terhadap kualitas layanan yang diberikan. Hal tersebut menunjukkan bahwa sebanyak 63,3\% keluhan terhadap kualitas layanan.

Kualitas layanan adalah upaya pemenuhan kebutuhan dan keinginan konsumen serta ketepatan penyampaiannya dalam mengimbangi harapan konsumen (Tjiptono, 2007 dalam Raharjo and Amboningtyas, 2017). Dalam kualitas layanan terdapat lagi 5 dimensi pokok yaitu, bukti fisik (tangible), keandalan (reliability), jaminan (assurance), ketanggapan (responsiveness), dan empati (empathy) yang dikemukakan oleh Parasuraman et al. (1993) dalam Faradisa et al. (2016).

Menurut Ratnasari dan Aksa (2011: 107) dalam Fitria dan Hidayat (2017) menunjukkan bahwa kualitas layanan sebagai perbandingan antara persepsi konsumen atas pelayanan yang nyata mereka terima dengan pelayanan sesungguhnya yang diharapkan. Hal ini sangat penting dalam proses keputusan pembelian karena kualitas pelayanan juga merupakan faktor penting dalam mewujudkan tujuan penjualan perusahaan terhadap konsumen karena diharapkan dapat memberikan pengaruh positif terhadap meningkatnya profit dan pengembangan perusahaan.

Berdasarkan latar belakang tersebut, peneliti melakukan penelitian mengenai pengaruh dimensi kualitas layanan terhadap keputusan pembelian konsumen Pao Pao.

\section{TINJAUAN PUSTAKA \\ Bukti Fisik (Tangible)}

Menurut Parasuraman et al. (1998) dalam Rizqy et al. (2016) bukti fisik (tangible) yaitu kemampuan suatu perusahaan dalam menunjukkan eksistensinya kepada pihak eksternal. Penampilan dan kemampuan sarana dan prasarana fisik perusahaan yang dapat diandalkan serta keadaan lingkungan. Bukti fisik (tangible), meliputi fasilitas fisik, perlengkapan, pegawai, dan sarana komunikasi.

\section{Keandalan (Reliability)}

Menurut Parasuraman et al. (1993) dalam Faradisa et al. (2016) adanya kemampuan dalam memberikan pelayanan kepada pelanggan dengan tepat waktu dan akurat. Menurut Ramdan (2008) dalam Rizqy et al. (2016) atribut-atribut yang ada dalam dimensi keandalan adalah:

1) Memberikan pelayanan sesuai janji.

2) Pertanggungjawaban tentang penanganan konsumen akan masalah pelayanan.

3) Memberikan pelayanan yang baik saat kesan pertama kepada konsumen dan tidak membedakannya satu dengan yang lainnya.

4) Memberikan pelayanan tepat waktu.

5) Memberikan informasi kepada konsumen mengenai kapan pelayanan yang telah dijanjikan itu akan direalisasikan.

\section{Jaminan (Assurance)}

Jaminan (assurance) yakni perilaku para karyawan yang mampu menumbuhkan kepercayaan pelanggan terhadap perusahaan dan bisa menciptakan rasa aman bagi para pelanggannya (Tjiptono, 2011: 198 dalam Wirawan, 2017). Menurut Lupiyoadi dan Hamdani (2006) dalam Rizqy et al. (2016) jaminan meliputi beberapa komponen, antara lain: 
- Komunikasi (communication), yaitu secara terus-menerus memberikan informasi kepada konsumen dalam bahasa dan penggunaan kata yang jelas sehingga para konsumen dapat dengan mudah mengerti apa yang diinformasikan pegawai serta dengan cepat dan tanggap menyikapi keluhan dan komplain dari para konsumen.

- Kredibilitas (credibility), perlunya jaminan atas suatu kepercayaan yang diberikan kepada konsumen, believability atau sifat kejujuran, menanamkan kepercayaan, memberikan kredibilitas yang baik bagi perusahaan pada masa yang akan datang.

- Keamanan (security), adanya suatu kepercayaan yang tinggi dari konsumen akan pelayanan yang diterima. Tentunya pelayanan yang diberikan mampu memberikan suatu jaminan kepercayaan.

- Kompetensi (competence) yaitu keterampilan yang dimiliki dan dibutuhkan agar dalam memberikan pelayanan kepada konsumen dapat dilaksanakan dengan optimal.

- Sopan santun (courtesy), yaitu adanya suatu nilai moral dalam pelayanan yang dimiliki oleh perusahaan dalam memberikan pelayanan kepada konsumen.

\section{Ketanggapan (Responsiveness)}

Tjiptono (2011: 198), dalam Maukar et al. (2015) menyatakan bahwa daya tanggap (responsiveness) berkenaan dengan kesediaan dan kemampuan para karyawan untuk membantu para pelanggan dan merespon permintaan mereka, serta menginformasikan kapan pelayanan akan diberikan dan kemudian memberikan pelayanan secara cepat. Menurut Maddox (1998) dalam Sugandhy et al. (2016) dimensi responsiveness diukur sebagai berikut:

- Memberikan pelayanan dengan cepat.

- Ketanggapan karyawan dalam menghadapi keluhan.

- Tanggap membantu pelanggan.

- Tanggap dalam menangani kebutuhan pelanggan.

\section{Empati (Empathy)}

Tjiptono (2011: 198) dalam Maukar et al. (2015) menyatakan bahwa empati (empathy) berarti bahwa perusahaan memahami masalah para pelanggannya dan bertindak demi kepentingan pelanggan, serta memberikan perhatian personal kepada pelanggan dan memiliki jam operasi yang nyaman. Menurut Maddox (1998) dalam Sugandhy et al. (2016) dimensi empathy diukur sebagai berikut:

- Memberikan perhatian individual dan perhatian personal.

- Kesungguhan karyawan dalam mengutamakan kepentingan pelanggan.

- Kemampuan karyawan memperlakukan pelanggan dengan penuh perhatian.

- Jam operasional sesuai.

- Karyawan mengetahui kepentingan pelanggannya.

\section{Keputusan Pembelian}

Menurut Assauri (2004: 79) dalam Hakim dan Yahya (2016) keputusan pembelian adalah suatu proses pengambilan keputusan akan pembelian yang mencakup penentuan apa yang akan dibeli atau tidak melakukan pembelian dan keputusan itu diperoleh dari kegiatan-kegiatan sebelumnya. Menurut Kotler dan Armstrong (2008: 179) dalam Fitria dan Hidayat (2017) proses pengambilan keputusan untuk 
melakukan pembelian atau tidak melalui beberapa tahapan sebagai berikut:

a. Pengenalan kebutuhan (need recognition) di mana proses pembelian dimulai dengan pengenalan kebutuhan yaitu masa di mana pembeli menyadari suatu masalah atau kebutuhan.

b. Pencarian informasi (information search) yaitu tahapan di mana konsumen mencari berbagai informasi terkait dengan masalah atau kebutuhan yang timbul.

c. Evaluasi alternatif (evaluation alternative) yaitu tahapan bagaimana konsumen menggunakan informasi untuk mengevaluasi berbagai merek alternatif di dalam serangkaian pilihan.

d. Keputusan pembelian (purchase decision) adalah tindakan konsumen yang mempunyai pilihan dan siap untuk melakukan pembelian.

e. Perilaku pasca pembelian (post purchase behaviour) yaitu perilaku dari pembeli pasca pembelian menentukan kepuasan atau ketidakpuasan pembeli terhadap suatu pembelian yang terletak pada hubungan antara sesuatu yang diharapkan konsumen dengan kinerja produk yang dirasakannya.

\section{HIPOTESIS PENELITIAN}

Hipotesis yang diajukan dalam penelitian ini adalah sebagai berikut:

$\mathrm{H}_{1}$ : Bukti fisik (tangible) berpengaruh secara signifikan terhadap keputusan pembelian pada konsumen Pao Pao.

$\mathrm{H}_{2}$ : Keandalan (reliability) berpengaruh secara signifikan terhadap keputusan pembelian pada konsumen Pao Pao.

$\mathrm{H}_{3}$ : Jaminan (assurance) berpengaruh secara signifikan terhadap kepu- tusan pembelian pada konsumen Pao Pao.

$\mathrm{H}_{4}$ : Ketanggapan (responsiveness) berpengaruh secara signifikan terhadap keputusan pembelian pada konsumen Pao Pao.

$\mathrm{H}_{5}$ : Empati (empathy) berpengaruh secara signifikan terhadap keputusan pembelian pada konsumen $\mathrm{Pao}$ Pao.

\section{METODE PENELITIAN \\ Populasi dan Sampel}

Populasi adalah keseluruhan jumlah yang terdiri atas objek atau subjek yang mempunyai karakteristik dan kualitas yang ditetapkan oleh peneliti untuk diteliti dan kemudian ditarik kesimpulannya (Sujarweni, 2015: 80). Populasi yang digunakan dalam penelitian ini adalah 63 orang konsumen Pao Pao. Sampel adalah bagian dari sejumlah karakteristik yang dimiliki oleh populasi yang digunakan untuk penelitian (Sujarweni, 2015: 81). Teknik sampling yang digunakan dalam penelitian ini adalah nonprobability sampling dengan menggunakan teknik sampling jenuh. Teknik penentuan sampel ini digunakan bila semua anggota populasi digunakan sebagai sampel (Sujarweni, 2015: 88). Oleh karena itu, peneliti mengambil sampel sebanyak 63 orang.

\section{Metode Pengumpulan Data}

Metode pengumpulan data dalam penelitian ini menggunakan data primer dan data sekunder. Data primer yang digunakan adalah kuesioner. Kuesioner penelitian diberikan kepada 63 orang konsumen Pao Pao. Kuesioner merupakan teknik pengumpulan data yang dilakukan dengan cara memberi seperangkat pertanyaan atau pernyataan tertulis kepada para responden 
untuk dijawab (Sujarweni, 2015: 94). Penggunaan kuesioner menggunakan skala Likert dengan ketentuan sebagai berikut:
1. STS : Sangat Tidak Setuju
2. TS : Tidak Setuju
3. $\mathrm{N}$ : Netral
4. S : Setuju
5. SS : Sangat Setuju

Data sekunder yang digunakan adalah jurnal, buku, dan internet.

\section{HASIL PENELITIAN DAN PEMBAHASAN \\ Uji Validitas dan Reliabilitas}

Hasil pengujian validitas menunjukkan bahwa semua instrumen pernyataan dari variabel bukti fisik (tangible), keandalan (reliability), jaminan (assurance), ketanggapan (responsiveness), empati (empathy), dan keputusan pembelian mempunyai nilai signifikansi (Sig. 2-tailed) 0,000 $\leq 0,05$. Dengan demikian dapat disimpulkan bahwa nilai signifikansi (Sig. 2-tailed) kurang dari 0,05, sehingga semua kuesioner yang digunakan valid dan dapat digunakan untuk mengukur variabelvariabel yang ada dalam penelitian. Hasil pengujian realibilitas seperti terlihat pada Tabel 1.

Tabel 1

Hasil Uji Reliabilitas

\begin{tabular}{|l|c|c|}
\hline \multicolumn{1}{|c|}{ Variabel } & $\begin{array}{c}\text { Cronbach's } \\
\text { Alpha }\end{array}$ & Kesimpulan \\
\hline $\begin{array}{l}\text { X1 Bukti fisik } \\
\text { (Tangible) }\end{array}$ & 0,760 & Reliabel \\
\hline $\begin{array}{l}\text { X2 Keandalan } \\
\text { (Reliability) }\end{array}$ & 0,820 & Reliabel \\
\hline $\begin{array}{l}\text { X3 Jaminan } \\
\text { (Assurance) }\end{array}$ & 0,872 & Reliabel \\
\hline $\begin{array}{l}\text { X4 Ketanggapan } \\
\text { (Responsiveness) }\end{array}$ & 0,867 & Reliabel \\
\hline $\begin{array}{l}\text { X5 Empati } \\
\text { (Empathy) }\end{array}$ & 0,625 & Reliabel \\
\hline $\begin{array}{l}\text { Y Keputusan } \\
\text { Pembelian }\end{array}$ & 0,722 & Reliabel \\
\hline
\end{tabular}

Data dari Tabel 1 menunjukkan bahwa semua variabel dari variabel bukti fisik (tangible), keandalan (reliability), jaminan (assurance), ketanggapan (responsiveness), empati (empathy), dan keputusan pembelian mempunyai nilai Cronbach's Alpha $\geq 0,6$. Oleh karena itu dapat disimpulkan bahwa semua variabel yang digunakan reliabel dan dapat digunakan untuk penelitian selanjutnya.

\section{Uji Asumsi Klasik Uji Normalitas}

Hasil uji normalitas menunjukkan bahwa nilai signifikan yang diperoleh sebesar $0,200 \geq 0,05$, sehingga dapat disimpulkan bahwa variabel bebas dan terikat yang digunakan dalam penelitian dapat terdistribusikan secara normal.

\section{Uji Autokorelasi}

Hasil uji autokorelasi menunjukkan bahwa nilai Durbin-Watson adalah 2,079. Dilihat dari tabel Durbin-Watson nilai dU dengan jumlah variabel bebas 5 dan jumlah sampel 63 adalah 1,7671 dan diketahui nilai (4-dU) adalah 2,233. Sehingga dapat disimpulkan bahwa 1,7671 < $2,079<2,233$ yang berarti tidak terjadi masalah autokorelasi.

\section{Uji Multikoliniearitas}

Nilai VIF (Variance Inflation Factor) pada variabel bebas bukti fisik (tangible), keandalan (reliability), jaminan (assurance), ketanggapan (responsiveness), dan empati (empathy) kurang dari 10. Dari hasil ini dapat disimpulkan bahwa pada model regresi yang dipergunakan dalam penelitian tidak terjadi multikolinearitas antar variabel bebas. 


\section{Uji Heteroskedastisitas}

Nilai signifikan variabel bukti fisik (tangible) 0,933, keandalan (reliability) 0,227, jaminan (assurance) 0,314 , ketanggapan (responsiveness) 0,906, dan empati (empathy) 0,409. Dari hasil tersebut dapat dilihat bahwa nilai signifikansi variabel bukti fisik (tangible), keandalan (reliability), jaminan (assurance), ketanggapan (responsiveness), dan empati (empathy) > 0,05 . Sehingga dapat disimpulkan bahwa tidak terdapat adanya suatu heterokedastisitas yaitu terdapat kesamaan varian dari residual satu pegamatan ke pengamatan lain.

\section{Uji Linearitas}

Hubungan antar variabel bukti fisik (tangible), keandalan (reliability), jaminan (assurance), ketanggapan (responsiveness), empati (empathy) dengan keputusan pembelian bersifat linear, karena memiliki nilai signifikansi $0,000<0,05$. Dari hasil tersebut dapat disimpulkan tidak terjadi masalah pada uji linearitas.

\section{Analisis Regresi Berganda}

Persamaan yang diperoleh dari hasil analisis regresi berganda berdasarkan data dari Tabel 2 adalah sebagai berikut:

$$
\begin{gathered}
\mathrm{Y}=1,709+0,111 \mathrm{X} 1+0,108 \mathrm{X} 2+ \\
0,117 \mathrm{X} 3+0,058 \mathrm{X} 4+0,311 \mathrm{X} 5
\end{gathered}
$$

$\mathrm{Y}=$ keputusan pembelian

$\mathrm{X} 1=$ Tangible

$\mathrm{X} 2=$ Reliability

$\mathrm{X} 3=$ Assurance

$\mathrm{X} 4=$ Responsiveness

X5= Empathy

Persamaan regresi linear tersebut menunjukkan bahwa koefisien regresi bukti fisik (tangible), keandalan (reliability), jaminan (assurance), ketanggapan (responsiveness), dan empati (empathy) bernilai positif terhadap keputusan pembelian konsumen $\mathrm{Pao}$ Pao.

Tabel 2

\begin{tabular}{|c|c|c|c|c|}
\hline \multicolumn{5}{|c|}{ Coefficients $^{\mathrm{a}}$} \\
\hline \multicolumn{2}{|c|}{ Model } & Unstandardized & & Sig. \\
\hline \multirow{6}{*}{1} & (Constant) & 1709 & 7943 & 0000 \\
\hline & Tangible (x1) & 0,111 & 2,427 & 0.018 \\
\hline & $\begin{array}{l}\text { Reliability } \\
\text { (x2) }\end{array}$ & 0,108 & 2,609 & 0,012 \\
\hline & $\begin{array}{l}\text { Assurance } \\
\text { (x3) }\end{array}$ & 0,117 & 3,680 & 0,001 \\
\hline & $\begin{array}{l}\text { Responsivenss } \\
\text { (x4) }\end{array}$ & 0,058 & 2,016 & 0,049 \\
\hline & Empathy (x5) & 0,311 & 4,204 & 0,000 \\
\hline \multicolumn{5}{|c|}{ a. Dependent Variable: Keputusan Pembelian (y) } \\
\hline
\end{tabular}

Hasil Analisis Regresi Berganda

Berdasarkan data dari Tabel 2 persamaan regresi bukti fisik (tangible) menunjukkan nilai koefisien regresi sebesar 0,111, yang berarti jika bukti fisik (tangible) mengalami kenaikan satu satuan, maka keputusan pembelian akan meningkat juga sebesar 0,111. Persamaan regresi keandalan (reliability) menunjukkan nilai koefisien regresi sebesar 0,108 , yang berarti jika keandalan (reliability) mengalami kenaikan satu satuan, maka keputusan pembelian akan meningkat juga sebesar 0,108 . Persamaan regresi jaminan (assurance) menunjukkan nilai koefisien regresi sebesar 0,117, yang berarti jika jaminan (assurance) mengalami kenaikan satu satuan, maka keputusan pembelian akan meningkat juga sebesar 0,117. Persamaan regresi ketanggapan (responsiveness) menunjukkan nilai koefisien regresi sebesar 0,058 , yang berarti jika ketanggapan (responsiveness) mengalami kenaikan satu satuan, maka keputusan pembelian 
akan meningkat juga sebesar 0,058. Persamaan regresi empati (empathy) menunjukkan nilai koefisien regresi sebesar 0,311, yang berarti jika empati (empathy) mengalami kenaikan satu satuan, maka keputusan pembelian akan meningkat juga sebesar 0,311 .

\section{Uji F}

Nilai sig. uji $\mathrm{F}$ lebih kecil dari 0,05 yaitu $0,000(0,000 \leq 0,05)$. Sehingga dapat disimpulkan bahwa uji model ini layak digunakan dalam penelitian (good of fit).

\section{Uji t}

Variabel tangible (X1) mempunyai nilai signifikansi uji t $0,018<$ 0,05 , yang berarti bahwa variabel tangible (X1) berpengaruh secara signifikan terhadap keputusan pembelian (Y). Kemudian nilai signifikansi uji $\mathrm{t}$ variabel reliability $(\mathrm{X} 2)$ 0,012 $<0,05$ yang menunjukkan bahwa variabel reliability (X2) berpengaruh secara signifikan terhadap keputusan pembelian (Y). Nilai signifikansi uji t variabel assurance $(\mathrm{X} 3)$ 0,001 < 0,05, yang berarti variabel assurance (X3) memiliki pengaruh secara signifikan terhadap keputusan pembelian (Y). Variabel responsiveness (X4) memiliki nilai signifikansi uji t $0,049<0,05$ yang berarti variabel responsiveness (X4) memiliki pengaruh signifikan terhadap keputusan pembelian (Y). Kemudian, variabel empathy (X5) memiliki nilai signifikansi uji t $0,000<0,05$ yang berarti variabel empathy (X5) berpengaruh secara signifikan terhadap keputusan pembelian (Y).

\section{Koefisien Determinasi $\left(\mathbf{R}^{\mathbf{2}}\right)$}

Nilai koefisien determinasi sebesar 0,728. Hal ini menunjukkan bahwa proporsi pengaruh variabel bukti fisik (tangible), keandalan (reliability), jaminan (assurance), ketanggapan (responsiveness), dan empati (empathy) terhadap keputusan pembelian sebesar $72,8 \%$, sedangkan $27,2 \%$ dipengaruhi oleh variabel lain diluar variabel bukti fisik (tangible), keandalan (reliability), jaminan (assurance), ketanggapan (responsiveness), dan empati (empathy).

\section{SIMPULAN}

1. Bukti fisik (tangible) berpengaruh secara signifikan terhadap keputusan pembelian pada konsumen Pao Pao, sehingga hipotesis pertama dalam penelitian ini diterima.

2. Keandalan (reliability) berpengaruh secara signifikan terhadap keputusan pembelian pada konsumen Pao Pao, sehingga hipotesis kedua dalam penelitian ini diterima.

3. Jaminan (assurance) berpengaruh secara signifikan terhadap keputusan pembelian pada konsumen Pao Pao, sehingga hipotesis ketiga dalam penelitian ini diterima.

4. Ketanggapan (responsiveness) berpengaruh secara signifikan terhadap keputusan pembelian pada konsumen Pao Pao, sehingga hipotesis keempat dalam penelitian ini diterima.

5. Empati (empathy) berpengaruh secara signifikan terhadap keputusan pembelian pada konsumen Pao Pao, sehingga hipotesis kelima dalam penelitian ini diterima.

\section{SARAN}

1. Pao Pao perlu membuat desain packaging baru yang lebih menarik agar konsumen dapat tertarik dan memutuskan untuk membeli.

2. Pao Pao harus lebih memperhatikan kebersihan dan kerapian produk 
Pao Pao meninggalkan kesan yang baik kepada konsumen.

3. Pao Pao diharapkan bisa mengantarkan produk dengan tepat waktu dan akan melayani konsumen dengan baik dan sopan, serta menerapkan moto $3 \mathrm{~S}$ senyum, salam, sapa setiap saat agar dapat mempertahankan pelanggan Pao Pao.

4. Pao Pao perlu memberikan ganti rugi jika terjadi kesalahan dalam pelayanan. Serta dapat menerima keluhan dari konsumen serta memperbaikinya di masa yang akan datang.

5. Pao Pao diharapkan memberikan respon yang cepat ketika konsumen bertanya mengenai produk dan ingin melakukan pemesanan.

6. Pao Pao diharapkan memberikan informasi tentang produk dan meminta feedback sebagai masukan bagi perusahaan.

7. Bagi peneliti selanjutnya yang ingin melakukan penelitian dengan judul yang sama, diharapkan dapat menambah variabel lain seperti kualitas produk atau promosi yang dapat mempengaruhi keputusan pembelian.

\section{DAFTAR KEPUSTAKAAN}

Ayu, A. F., dan Zulhelmi, 2015, Analisis Faktor-Faktor yang Mempengaruhi Keputusan Pembelian di SMP Kristen Kalam Kudus Pekanbaru, Jurnal Ilmiah Manajemen, Vol. 3, No. 3.

Basri, N. A., R. Ahmad, F. I. Anuar, and A. K. Ismail, 2016, Effect of Word of Mouth Communication on Customer Purchase Decision: Malay Upscale Restaurant, Procedia, Vol. 222, page 324-331.
BPS, 2016, Rata Rata Pengeluaran Perkapita Sebulan Menurut Kelompok Barang 2013-2016, diambil kembali dari www.bps.go.id: https: //www.bps.go.id/statictable/2014/1 2/18/966/rata-rata-pengeluaran-perkapita-sebulan-menurut-kelompokbarang-rupiah-2013-2016.html, diakses tanggal 2 Februari 2018.

Faradisa, I., L. Budi, dan M. M. Minarsih, 2016, Analisis Pengaruh Variasi Produk, Fasilitas, dan Kualitas Pelayanan Terhadap Minat Beli Ulang Konsumen pada Indonesian Coffeeshop Semarang (ICOS CAFÉ), Journal of Management, Vol. 2, No. 2.

Fitria, A., dan I. Hidayat, 2017, Pengaruh Bauran Pemasaran, Kualitas Pelayanan Terhadap Keputusan Pembelian pada Kupunya Rumah Mode, Jurnal Ilmu, dan Riset Manajemen, Vol. 6, No. 4.

Hakim, M. M., dan Yahya, 2016, Pengaruh Kualitas Layanan, Harga, Lokasi, dan Promosi Terhadap Keputusan Pembelian, Jurnal Ilmu, dan Riset Manajemen, Vol. 5, No. 11 .

Maukar, F. J., L. Kawet, dan L. O. Dotulong, 2015, Pengaruh Reliability, Responsiveness, Assurance, Empathy, dan Tangibles Terhadap Peningkatan Penjualan pada PT JCO Donuts \& Coffee Manado, Jurnal EMBA, Vol. 3, No. 2, hal. 213-224.

Natalia, V., 2016, Dampak Kinerja Pelayanan Jasa Terhadap Keputusan Pembelian Sepeda Motor Yamaha Mio pada PT. Aneka Makmur Sejahtera di Pontianak, Bisma, Vol. 1, No. 2. 
Rachman, A., P. D. Paramita, H. S. Wulan, dan Darsin, 2017, Strategi Kepuasan Konsumen yang Berdampak Minat Beli Ulang Melalui Bauran Pemasaran, Kualitas Produk dan Ekuitas Merek Pada PT. Intertobacco Utama Industry $\mathrm{Ku}$ dus, Journal of Management.

Raharjo, C. A., and D. Amboningtyas, 2017, The Effect of Service Quality, Price, and Brand Image on Customer Loyalty with Customer Satisfaction as Moderating on The Point "Barokah" Sikopek, Journal of Management.

Rashid, I. M., M. J. Rani, B. N. Yusuf, and M. S. Shaari, 2015, The Impact of Service Quality and Customer Satisfaction on Customer's Loyalty: Evidence from Fast Food Restaurant of Malaysia, International Journal of Information, Business, and Management, Vol. 7, No. 4.

Rizqy, R. R., M. M. Warso, dan A. Fathoni, 2016, Pengaruh Kualitas Pelayanan Terhadap Kepuasan Konsumen, Journal of Management, Vol. 2, No. 2.

Sari, R. K., D. Yulisetiarini, dan Surdyanto, 2016, Pengaruh Harga, dan Kualitas Pelayanan Serta Kualitas Produk Terhadap Minat Pembelian Ulang, dan Kepuasan Pelanggan Online Shopping pada Mahasiswa Universitas Abdurachman Saleh Situbondo, Bisma Journal Bisnis, dan Manajemen, Vol. 10, No. 2, hal. 115-126.
Sinaga, H., 2016, Pengaruh Kualitas Pelayanan, dan Citra Merek Terhadap Keputusan Pembelian pada PT. Merindo Antaloka, Jurnal Ilmiah Maksitek, Vol. 1, No. 1.

Sugandhy, C., G. Odelia, dan A. Nugroho, 2016, Analisa Pengaruh Kualitas Layanan Terhadap Loyalitas Pelanggan di Restoran X Surabaya, Jurnal Hospitality, dan Manajemen Jasa, Vol. 4, No. 1.

Sugiyono, 2017, Metode Penelitian Kuantitatif, Kualitatif, dan R\&D, Alfabeta, Bandung.

Sujarweni, V. W., 2015, Metodologi Penelitian Bisnis \& Ekonomi, Pustaka Baru Press, Yogyakarta.

Suryani, D. A., J. Wibowo, dan A. Y. Fianto, 2016, Analisis Pengaruh Kualitas Layanan, dan Kualitas Informasi Website Terhadap Kualitas Website E-Commerce Menggunakan Metode Webqual, JSIKA, Vol. 5, No. 11.

Syahrial, H., dan M. Rizan, 2015, Pengaruh Tangible, Empathy, dan Assurance Terhadap Keputusan Pembelian pada PT. Raden Auto Jakarta, Jurnal Manajerial, Vol. 9, No. 1, hal. 41-50.

Wirawan, R., 2017, Pengaruh Dimensi Kualitas Pelayanan Terhadap Kepuasan Wajib Pajak di Kabupaten Lumajang, Jurnal Ilmiah Ilmu Akuntansi, Keuangan, dan Pajak, Vol. 1, No. 2. 